\title{
O design como processo e a questão da autoria
}

\section{Leonardo Pinto de Almeida}

Doutor; Universidade Federal Fluminense

leonardo.p.almeida@gmail.com

\section{Romulo Miyazawa Matteoni}

Doutor; Pontifícia Universidade Católica Rio de Janeiro

matteodesigner@gmail.com

\section{Resumo}

O presente artigo tem como objetivo analisar o trabalho do design e sua relação com a autoria. Discutimos o lugar desempenhado pela figura autoral no design à luz de uma reflexão sobre a dimensão projetual do trabalho do designer. Levamos em conta, assim, os produtos desta forma laboral como eventos isolados em ciclo espiralizado de desenvolvimento constante.

\section{Palavras-chave}

Epistemologia. Autoria. Processo de design.

\section{Introdução}

0 presente artigo visa a analisar o trabalho do design como projeto à luz dos problemas relativos à autoria e à criação na contemporaneidade. Para tanto, focaremos sobre questões relativas à técnica, à criação, ao projeto, à gestão e à autoria. A tensão epistemológica do design como um campo tomado pela técnica e pela criação se evidencia em nossa reflexão.

A questão inicial a ser pensada, como alicerce de nossa argumentação, está relacionada ao trabalho do designer em sua criação projetual. Normalmente, o profissional do campo transforma objetos existentes em uma determinada ecologia, através da técnica e do processo projetual, em objetos preferíveis - os quais se tornam instrumentos para o pensamento, ferramentas que mobilizam ações que mudam a relação entre homem e 
espaço, influindo na construção das rotinas cotidianas, desde as tarefas corriqueiras até a gestão do espaço laboral.

Exemplos claros são as metáforas visuais do escritório, representadas pelas interfaces digitais tão presentes em nosso repertório cultural contemporâneo, ou mesmo, as atitudes naturais despertadas diante de uma tela (antes passível de representar um conteúdo visual, hoje passível de responder visualmente a um estímulo físico). A formação de uma nova cultura de comunicação a partir da criação, popularização e sofisticação de aparelhos móveis que, se antes possuíam apenas as qualidades de um telefone portátil, hoje, enquanto smartphones possibilitam carregar neles uma extensão de nossos arquivos de trabalho, repositório de idéias e arquivo pessoal, além de ser um dispositivo com fins comunicacionais múltiplos (agregando e-mails, telefones, mensagens, aplicativos para chat, etc). Isso acarreta a geração de uma nova cultura relativa aos usos e às possibilidades de tais artefatos.

Esse trabalho de construção de instrumentos é uma verdadeira ressignificação dos objetos. 0 processo projetual, em sua trama criativa, transgride aos usos corriqueiros dos objetos existentes, para se tornar obra, ou melhor, para se tornar instrumentos, marcas, interfaces ou produtos.

O nome do autor, no sentido dado por Foucault (2001) em $O$ que é um autor?, está justamente associado à marcação do território referencial posterior ao exercício do trabalho intelectual e artístico. Nesse caso, o nome do designer ou produtor da peça se encontra, como alicerce referencial desse produto inventado, no processo projetual criativo. 0 nome do autor seria a ponta do processo, ou seja, o que dá peso, significado e referência ao projeto. Esse nome sustenta os usos do objeto, inventado no projeto, pela gestão do espaço laboral e, ainda, aglutina objetos do passado e do presente a ele relacionados, criando uma teia de significações que possibilita um prévio entendimento do artefato e da criação de um horizonte de expectativas relacionadas a tal nomenclatura.

Neste sentido, o aspecto histórico e diacrônico da filosofia da linguagem de Bakhtin (2006) mostra-se fundamental para entender tal dinâmica. Assim, levaremos em conta também as reflexões bakhtinianas sobre a autoria coletiva, para mostrar como a criação está associada intrinsecamente às ressignificações dos sentidos que nos atravessam hodiernamente. Isso nos ajudará a pensar sobre como a criação do design está em diálogo constante com seu tempo, uma vez que essa prática criativa é nesse campo, muitas vezes, fruto de recriações de objetos, produzindo novos sentidos e usos para estes, seja no 
pensamento seja no espaço laboral. 0 design viabiliza ferramentas importantes para o trabalho na atualidade, já que seus projetos exigem de seus usuários competências e habilidades específicas. É nesse sentido que a atividade do design cria instrumentos e ao criá-los, reinventa funcionalidades objetais.

O diálogo entre autores de áreas diversas (linguística, comunicação, psicologia, filosofia) e do campo do design, tematizado pela compreensão histórica diacrônica do processo projetual, abre novas frentes de discussão e possibilita novos entendimentos acerca de uma prática baseada na constante pesquisa (levantamento de dados e construção de casos), experimentação (indução de contextos pesquisados) e inovação dissociada do conceito de "novo", mas atrelada ao conceito de ressignificação e da experiência de uso dos objetos.

Relacionando as visões sobre o campo em questão expressas por Couto (1997), Love (2002), Bomfim (1997), a perspectiva histórica da cultura de projeto de Argan (1992), os conceitos de comunicação criados por Bakhtin (2006) e a função autor trabalhada por Foucault (2001), propomos discutir os lugares da autoria nos projetos de design, levando em conta a hipótese de que os produtos são pontos de um ciclo em constante desenvolvimento espiral.

\section{A interferência projetual do design}

O designer produz artefatos que se inserem no tecido social. Suas criações ganham relevância no uso cotidiano, gerando novos valores na interação com outros objetos. No desenvolvimento de seu trabalho, ele conjuga elementos simbólicos da comunidade à qual visa atingir, os decodificando e reorganizando na forma de diferentes discursos. Nesse sentido, propõe novas significações para as unidades conjugadas. Pode-se dizer, portanto, que se trata de um profissional capacitado a usar linguagens e gerar enunciações a cada produção.

Em sua interferência no mundo, o designer atua como construtor de discursos, concatenando diferentes linguagens com diversos fins. Os frutos do trabalho desse profissional podem ser uma interface para o acesso a um conteúdo digital, uma linha de camisas, um carro ou, porque não, uma cadeira. Todos parecem ter pouco em comum, mas, essencialmente, possuem ao menos duas características que os unem como produtos de design: são resultantes de um processo projetual e trazem consigo valores simbólicos, a partir dos quais comunicam com diferentes nichos da sociedade, recebendo novos usos e 
novas significações. Assim, afirmamos que o processo projetual é criador de valor simbólico. Ele desenvolve ferramentas para pensar, trabalhar e viver, a partir de objetos antes existentes.

No processo projetual, o profissional converge diferentes linguagens traduzindo diversas informações para um público determinado. 0 artefato traz na forma (física ou gráfica) uma instrução de como ser usado e de sua finalidade para tal utilidade. Ele exige usos específicos, criados pelo projeto, mas também sugere que os usuários tenham competências especificas para melhor aproveitar o artefato em sua funcionalidade. Porém, em seu contexto social e histórico de uso, ao interagir com uma míriade de outros objetos, ganha novos usos e é ressignificado. Os objetos, tais como os signos, fazem parte de nossa expressão e de nossa construção de mensagens em diversos modos. Em seus lugares no mundo, como sua casa, por exemplo, o sujeito toma decisões que fazem com que aquele espaço transpareça valores relativos a ele. Como tal, o trabalho do designer constrói valores simbólicos que podem transformar os espaços onde os homens vivem e atuam profissionalmente.

Nessa perspectiva, consideramos o entendimento da mecânica expressiva, proposta por Bakhtin (2006), fundamental para a prática do design. Como um dos produtores de peças que se agregarão à malha comunicativa da sociedade, o designer deve se cercar de uma fundamentação teórica que permita a compreensão da dinâmica da interação social. 0 fruto de cada projeto será um elemento de discurso a ser articulado pelos grupos aos quais é endereçado. 0 processo projetual, desenvolvido a partir do mapeamento dos discursos e das práticas dos grupos a que se quer atingir, tende a se enriquecer com o entendimento de como os objetos influenciam a cultura.

Como Nietzsche (1984) nos lembra, o homem é o animal que valora. Por isso, a linguagem que tanto nos caracteriza como humanos é a ferramenta que valora nossas ações e os artefatos e instrumentos que atravessam nossa cultura. Esta última é intrinsecamente ligada ao valor. Desde sua raiz etimológica relacionada à agricultura, ao cultivo, até a cultura de massa associada ao consumo (EAGLETON, 2005; GUATTARI; ROLNIK, 2007). Tanto os objetos de pensamento quanto os artefatos e instrumentos transformam nosso modo de pensar e, por conseguinte, influenciam a cultura.

Os tipos de produtos propõem horizontes de expectativas, baseados nas similitudes com outros já existentes. Assim sendo, é importante pensar que, em sua estrutura, o artefato deva trazer as informações que permitam uma interação fluente por parte do público 
(KRIPPENDORF, 1995). Entendendo essa dinâmica e agregando-a ao processo, o designer pode não apenas desenvolver uma espécie de produto, mas enxergar as razões que o fazem daquela forma, buscando sempre a evolução de tal objeto. Os artefatos são pontos de uma rede intrincada, estabelecendo relações entre si por funções similares, valores simbólicos associados e proveniência, no tocante à produção ou à autoria.

No entanto, em um primeiro exame, o usuário potencial tende a buscar na forma do objeto ou da interface, pistas que permitam (a) produzir um entendimento inicial quanto ao uso e à função; (b) categorizar o produto; (c) criar horizontes de expectativas, em comparação com similares conceituais (quanto à função imaginada ou quanto ao ambiente e sua relação com o uso proposto); para enfim (d) significar o objeto. Assim, compreender o processo de construção de discurso traz elementos do uso da linguagem para guiar uma prática mais consciente e uma melhor avaliação do posicionamento do profissional em relação ao seu processo, ao produto gerado e ao contexto em que ele será usado.

0 design está associado tanto aos meios de comunicação quanto às renovações constantes do espaço laboral, em função de uma melhor produtividade. Isso faz ele ser tão contemporâneo. Lazzarato (2006), ao analisar as vicissitudes do trabalho na atualidade, afirma que as empresas antecipam a demanda de produtos, compreendendo que o marketing é criador de desejo e, por conseguinte, do público. Na sociedade contemporânea, o marketing se tornou aliado da empresa em sua invenção do público a ser afetado por sua dinâmica. 0 design em sua pedagogia do produto pode ser usado, nesse caso, como aliado ao marketing na criação de um público. Assim, o design passa a ser um motor de reflexão para a gestão do conhecimento tão discutida hodiernamente nas empresas. Mas essa é apenas uma de suas dimensões.

Deste modo, pensemos nos produtos desenvolvidos pelos designers como objetos que resultam de duas variantes: um projeto (a) que demanda a criação de um objeto para executar algumas funções; e (b) que seja viável em relação a sua fabricação, distribuição, circulação, uso e descarte. Antes de gerar um produto específico, com uma certa cor, uma certa dimensão, uma certa textura, o designer deve entender e tentar responder a questão que se coloca diante dele com sua criação. Uma série de requisitos e restrições delineia o produto como ele é. Um produto deve ser pensado quanto a sua pertinência e validade em ambientes e situações de uso antecipadas. Portanto, levamos em conta os ambientes em que será usado, as condições mercadológicas para sucesso ou fracasso (quais seriam as características das soluções mais utilizadas, o que possibilitaria seu sucesso ou a que seria 
condicionado seu fracasso), os instrumentos de legitimação (objetivos ou subjetivos) aos quais estará submetido, o gosto do público (bem como a definição dos públicos aos quais pretende atender), suas condições de fabricação, armazenamento e venda e seu transporte e circulação, bem como sua inserção numa época de diversidade cultural interplanetária e acesso fácil aos diversos meios de informação.

Por esses elementos, entendemos que, ao elencar condições para iniciar um projeto de design, o profissional parte da definição de uma oportunidade. Esta é vértice em torno do qual orbitarão elementos relativos : (a) aos usos e costumes contemporâneos, analisados por um viés diacrônico (situados historicamente) e abordados pelo ponto de vista de uma lacuna (uma possibilidade de atuação); (b) ao contexto de produção: questões de abordagem sustentável e horizonte de tecnologia social e material; (c) ao período de pesquisa e desenvolvimento: numa cultura da convergência, as ideias circulam por muitos meios e os contextos onde as oportunidades são enxergadas podem mudar em períodos muito curtos de tempo, o que acarreta maior repertório para a concretização de soluções, mais fontes de pesquisa de casos similares e maior flexibilidade nas variáveis ligadas ao público, à produção e ao horizonte de expectativas; e (d) ao período de experimentação.

Argan (1992) destaca que o projeto, por sua concepção transgressiva, é um projetar contínuo. Sendo ligado à capacidade de projeção, de reflexão sobre o passado e antecipação idealizada do futuro, ele é uma crítica sobre a existência, baseada na premissa de que seu agente pode desenvolver uma melhor resposta a uma dada questão que as respostas já existentes. Simon (1996) afirma que o design transforma situações existentes em situações preferíveis. É nesse contexto que o trabalho projetual é crítica e análise da existência. Ele toma a ecologia de objetos existentes como instância problemática e, por conseguinte, como motor da reflexão e criação projetual. Logo, quem projeta, usa a imaginação para antecipar tendências e criar uma possível solução melhor. No entanto, ao concretizar tal solução projetada, ele deixa o domínio do futuro ideal e passa ao domínio do presente real. Ao criar um objeto como solução, o designer realiza no projeto a redefinição de condições, a partir da mudança na relação entre os sujeitos e os objetos, possibilitando a redefinição de um pelo outro.

Neste caminho, ao ser posta em uso, a solução deixa o campo da imaginação, passando ao campo da história, sofrendo, então, um novo processo de análise, de crítica e de proposição de outra solução. 0 processo de projeto então não se encerra no seu objeto, mas o objeto, sim, passa a ser um novo dado para o processo de um novo projeto. Assim, tal 
perspectiva de projeto em design situa-se em consonância com a necessidade de renovação, inovação e proliferação da oferta de produtos sazonais que movimenta e alimenta a indústria atualmente (BAXTER, 2011).

Nesse sentido, recorremos à filosofia da linguagem para posicionar alguns conceitos. Um dos elementos mais importantes trazidos por Bakhtin (2003) em sua visão relativa à comunicação humana talvez seja o entendimento de que as formas significativas se alteram no uso e no tempo. Presente em toda sua obra, o conceito de que os signos são ressignificados na interação traz a dinâmica como elemento fundamental. Para o linguista russo, as formas e os usos não são definitivos, mas móveis e múltiplos, ganhando novos sentidos em sua utilização pelos diversos grupos sociais.

Na concepção bakhtiniana, no entanto, o tempo não é um fator de indeterminação, mas um plano onde a linguagem e a produção de sentidos estão inseridas. Englobando em suas formulações o entendimento de que as formas são polissêmicas e alteram-se no uso e no tempo, Bakhtin (2003) trabalha exclusivamente com as relações.

Tratando a linguagem como um sistema dialógico de signos, ele vê como elemento central da comunicação a interação, onde a produção de sentidos se faz possível, tanto para quem constrói quanto para quem recebe uma mensagem. A construção de uma mensagem baseia-se nas significações adquiridas pelo uso dos signos nos meios em que o indivíduo está. Do mesmo modo, a escolha e uso das formas obedecem a uma determinação do que se quer dizer e para quem se quer dizer.

Quem emite faz uso do repertório, buscando endereçar ao ouvinte um enunciado idealizado, trazendo aí, tanto os valores significativos compreendidos quanto os valores que acha que ele deve compreender. Assim, tudo que é comunicado traz vozes de outros - de onde o repertório é construído - e constitui uma mensagem única no tempo através da concatenação de influências diversas. Por essa visão, a comunicação é um ciclo espiralizado interminável, que alimenta os indivíduos e é alimentado a cada construção.

Na interação em sociedade, toda formulação é uma resposta à outra formulação. Não apenas pela acepção mais aceita, em que realmente se responde a algum estímulo direto, mas porque sempre se constrói um enunciado tendo em vista pontos refutados, questionados, com os quais se concorda ou os quais se retoma. Nenhuma comunicação é inerte, partindo da ausência absoluta de substância, mesmo a que quebra o silêncio absoluto. Tudo é reação a alguma forma de contato. 
Retomando Argan (1992), o design propõe-se constantemente à crítica do real, onde o presente é situação problemática e oportunidade de atuação que mobilizará a geração de uma solução. Tal solução é uma formulação que, concretizada, se torna parte da situação problemática, possibilitando nova formulação.

Essa constante processual do projeto em design tem relação com a própria epistemologia do campo. Cross (1982) entende que o designer tem um modo de conhecer. Este modo específico tem relação íntima com sua forma de operar teoria e prática e de realizar tal operação para buscar uma melhor definição dos problemas tratados. Para Cross (1982), enquanto pessoas do campo das ciências estudam uma questão a partir de uma estratégia centrada no problema e na descoberta de uma regra que o rege, pessoas do campo do design adotam uma estratégia focada no desenvolvimento de soluções para o problema apresentado. Deste modo, o agente da área produz soluções que podem satisfazer condições do cenário definido, em vez de buscar um sistema que possibilite a geração de uma única solução de excelência. Assim, o designer gera soluções não definitivas que ajudam a contextualizar o problema tratado, apontando para um desenvolvimento de melhores soluções.

Buchanan $\left(1992^{1}\right.$ apud COUTO 1997, p. 53) ergue um conceito-base para o campo, entendendo o design como "[...] atividade projetual de criação, recriação e avaliação de objetos, presentes no cotidiano das pessoas, assumindo diversas formas e operando em diferentes níveis". Segundo o autor, designers exploram integrações concretas para o conhecimento, que vão combinar teoria e prática com novos propósitos produtivos. Buchanan (1995) organiza a produção em design nos seguintes eixos: (a) comunicação simbólica e visual, (b) objetos materiais, (c) atividades e serviços organizados e (d) sistemas complexos ou ambientes para vivência, trabalho, diversão e aprendizado. Para o referido autor, o pensamento de design traz um padrão sistemático de invenção que não se baseia na categorização de objetos ou ideias, mas no seu reposicionamento. Este pensamento, então, permite ao designer trabalhar soluções baseadas não no redesenho de um objeto da mesma categoria, mas na utilização de uma entidade de outra categoria ou natureza para operar as ações necessárias à solução ou à definição mais detalhada do problema. 0 reposicionamento de um objeto, diz Buchanan (1995), dá contexto e orientação ao pensamento, mas sua aplicação como uma solução em novo cenário gera uma nova percepção da questão e fornece um novo caminho a ser explorado. 0 design, então, é campo de invenção e de

${ }^{1}$ BUCHANAN, R. Wicked problems in design thinking in design. Design Issues, London, v. 8, n. 2, p. 5-21, sept. 1992. 
requalificação de valores a partir da relação ensejada pelo resultado prático de uma inovação teórica.

Sendo assim, não há uma validação definitiva, mas pequenas validações que acontecem a partir do estímulo criado pela geração de soluções satisfatórias, originando um novo conjunto de dados que permitem o refinamento ou a reconstrução de hipóteses. Assim, no modo de atuar do designer, o foco é lançado na possibilidade de extrair dados a partir de tentativa de solução. Como vimos com Argan (1992), a continuidade, portanto, é uma condição do trabalho do designer.

A autoria no trabalho de design, portanto, é algo efêmero, uma vez que o processo de design é contínuo. A partir da definição de uma oportunidade de atuação, criamos soluções satisfatórias (produtos) que mudam os cenários onde agimos, propiciando então a busca por uma nova oportunidade que toma o universo de objetos e de sujeitos inscritos naquele cenário, como dados para uma nova solução satisfatória.

\section{Design como trabalho de intervenção sobre o real e a gestão do espaço laboral}

Como afirmamos anteriormente, o design está ligado à experimentação de soluções. 0 design como campo é atravessado pela interdisciplinaridade, por utilizar conceitos e elementos de diversas áreas do conhecimento - tais como a psicologia, a filosofia, a engenharia, a matemática e o marketing. 0 projeto, como ferramenta crítica do trabalho, tem como objetivo a intervenção sobre o real para ressignificar e renovar os objetos existentes em uma dada ecologia de objetos. Este movimento de ressignificação projetual é muito usado nas empresas contemporâneas. Tomemos, como exemplo, a mudança cultural no espaço de trabalho das empresas a partir de simples modificações nas relações entre os trabalhadores e seu ambiente. Com o intuito de ilustrar o caso, antes devemos apresentar um panorama do uso do design na gestão do espaço laboral.

Em um artigo sobre as relações do design com o taylorismo, o fordismo e o toyotisme, Hilali e Mathieu (2010) apresentam como essas concepções possibilitaram o surgimento de soluções na gestão da atividade. Através de um trabalho de gestão do espaço laboral, essas concepções transformaram a prática, produzindo uma revolução na indústria em nome da produtividade.

De acordo com Hilali e Mathieu (2010), Frederick Taylor se apoiou em um paradigma científico e com suas análises construiu um modelo produtivo de gestão a partir do design 
do instrumento de trabalho. Antes dele, o trabalho do operário era somente relacionado à força física. Seus estudos levaram a pensar em outros fatores, como os materiais a serem trabalhados, o material da ferramenta, o tamanho e a força do trabalhador. Assim, Taylor inseriu, na dinâmica de análise do espaço laboral, a questão relativa à manifestação do instrumento de trabalho. Esse design visava sobretudo a eficiência no trabalho e levou em conta elementos que hoje seriam facilmente associados aos estudos ergonômicos do trabalho.

Segundo Hilali e Mathieu (2010), Henry Ford acrescentou a esse problema a questão propriamente do espaço laboral, ou seja, os estudos sobre a arquitetura do atelier de trabalho. Os estudos e as concepções do design de trabalho de Ford apontavam que com menos deslocamentos supérfluos dos trabalhadores, a produtividade aumentaria com toda certeza. Assim, sua concepção aborda o design do espaço laboral a partir das relações entre a arquitetura da fábrica, as condições climáticas em que o trabalho é feito, a redução de riscos de acidentes e a produtividade. Esses quatro fatores são os objetos da concepção de design do trabalho em Ford.

Já o Toyotismo se apresenta como um diálogo entre o design de instrumento de trabalho e o design do espaço laboral encontrado nos dois anteriores. No entanto, essa concepção teve, como questão projetual, o desperdício observado nas empresas. Essa forma de pensar o espaço laboral aposta em um exame crítico da produção e da distribuição dos produtos, a partir de um modelo de gestão que ficou conhecido como a dos cinco zeros: zero defeito nas peças, zero dano às máquinas, zero estoque, zero demora e zero burocracia. Este modelo muito influenciou outras formas de gestão baseadas em métodos de gerenciamento como o just-in-time e na relevância dada ao relacionamento cooperativo entre gerentes e trabalhadores (HILALI; MATHIEU, 2010).

Como podemos observar, o trabalho do design pode ser de grande utilidade na gestão do espaço laboral. E como afirmamos anteriormente, por causa de sua contemporaneidade, o design é atravessado e atravessa as problemáticas levantadas pela atualidade. E, por isso, tomemos o espaço laboral e sua relação com o design na sociedade da informação.

Boyle (1996), em Shamans, Software and Spleens: Law and the Construction of the Information Society, analisa as vicissitudes da sociedade da informação, apontando a relação entre informação e economia na atualidade. Ele indica como a nossa cultura tende a 
homologizar a informação para torná-la um valor utilizável na sociedade². Manovich (2000), como Boyle (1996), afirma que a coleção de dados (informações), observáveis tanto no database quanto no navigable space, são elementos de valor simbólico que ganham, na sociedade atual, valor econômico.

Essa homologização da informação pode ser observável naquilo que Johnson (2001) chamou de interface. A interface são metaformas, metáforas visuais que tomam espaço no meio digital para tornar o caos informacional explorável, ou melhor, tornar as informações acessíveis. 0 desktop, os browsers são exemplos de interface. A criação de interfaces é um dos objetos de trabalho do design na atualidade. 0 design trabalha na busca de soluções criativas e rentáveis na disponibilização e facilitação no acesso à informação.

Devido às exigências da economia contemporânea, as empresas atualmente têm buscado, através do marketing, soluções para criar seu público-alvo. Além disso, as exigências da busca contínua do conhecimento suscitaram a implementação de soluções empresariais com o intuito de construir espaços de aprendizagem organizacional.

Por causa disso, o design tem tomado como questão a educação e a aprendizagem no âmbito organizacional, para apresentar soluções por meio de estudos relativos à disponibilização de informações em sites de empresas, em sistemas de e-learning, em interfaces refererentes à educação corporativa (BAYMA, 2004).

0 design da interface e das ferramentas digitais de aprendizagem possibilita que as empresas respondam às exigências da contemporaneidade e disponibilizem um espaço laboral condizente com essas questões.

Como vimos, o trabalho do design está no cerne das transformações de objetos, situações, problemas existentes em soluções, respostas e objetos e situações preferíveis. Essa dinâmica do trabalho nos aponta para a questão concernente ao papel da autoria no processo projetual.

\section{Trabalho do design e a questão da autoria}

Como assinalado anteriormente, o campo em questão é atravessado pelas questões relativas à criação e à técnica. Seria essa atividade um trabalho técnico ou um trabalho artístico? Essa é uma questão que produz um corte epistemológico na compreensão do seu campo profuso de atuação. Rita Couto (1997) adiciona um novo dado à definição dessa área.

\footnotetext{
20 conceito de homologization poderia ser definido da seguinte maneira: "uniformização dos valores seguindo os desejos de ordem e de coerência no meio". (ALMEIDA, 2007, p. 83).
} 
A pesquisadora trabalha em consonância com outros autores no que tange à dupla transitividade do design, considerando esta uma atividade (a) de premissa prática, mas baseada na constante dinâmica da teoria e prática, e (b) de caráter interdisciplinar, fruto da apropriação de teorias de campos associados, para alimentar essa dinâmica. No entanto, detalhando essa busca, Couto (1997) recorre a uma categoria já mencionada por Cross (1982), mas agora como parte fundamental da epistemologia do campo. Entendendo que a transitividade do design é algo que suplanta a categorização do design como arte ou ciência, ela localiza no viés tecnológico o mais preciso posicionamento do campo. Definindo tecnologia como "[...] um conjunto organizado de conhecimentos - científicos, empíricos ou intuitivos - pronto para ser empregado na produção e na comercialização de bens e serviços". (COUTO, 1997, p. 63). A autora considera "[...] adequado definir o design como uma tecnologia, um corpo organizado de conhecimento, com status de disciplina, que pode ser ensinado através de uma estrutura curricular adequada". (COUTO, 1997, p. 64). Ela destaca que em sua produção o design não deixa de recorrer tanto aos componentes da arte, como a estética, quanto aos componentes da ciência, usando "[...] conhecimentos científicos disponíveis para conferir desempenho funcional adequado aos objetos e sistemas materiais que concebe". (COUTO, 1997, p. 64). Para ela, o design utiliza enfoques metodológicos diversos, constituindo-se por suas especificidades como disciplina do campo da pesquisa de desenvolvimento e tecnologia operativa. No entanto, nossa tarefa não é desenvolver uma reflexão epistemológica sobre essa questão. Tomamos o design em seu trabalho para refletir sobre a autoria. Qual seria o papel do nome do autor na trama discursiva que leva do processo projetual à criação do produto?

Em $O$ que é um autor?, Foucault (2001) assinala o papel crucial do nome do autor na ordem dos discursos. $\mathrm{O}$ nome do autor funciona como um território discursivo que alicerça a sua recepção. Brunn (2001) concorda com essa questão ao afirmar que a mitologia autoral é derivada das relações traçadas na modernidade entre escrita, autor e obra.

A escrita literária ou o trabalho intelectual e artístico produz a obra e, por conseguinte, o autor, como referência. Ambos os elementos se retroalimentam nas relações de captura da criação. Eles são territórios que alicerçam nossas representações e relações com o trabalho executado.

Em Escrita \& Autoria: Internet, Literatura e Ontologia, Almeida (2014) constrói a ideia relativa às cinco dimensões da escrita: a ontológica, a legal, a jurídica, a estética e a 
referencial. A primeira é a dimensão relativa à criação propriamente dita, enquanto as outras quatro são mecanismos de captura que estão atrelados à figura autoral moderna.

A dimensão legal é aquela relativa à "apropriação penal dos discursos" (ALMEIDA 2014). Ela apareceu historicamente no momento em que a escrita passou a ser entendida como um crime qualquer. Em A aventura do livro, Chartier (1998) afirma que os primeiros casos sistemáticos de ordenação alfabética, por nome de autor, de livros a serem proibidos por seu caráter transgressivo, datam do século XVI. Essa apropriação penal dos discursos foi executada por meio de mecanismos repressivos associados às práticas do Estado e da Igreja.

Como se pode observar, esta dimensão se refere à responsabilização do suposto agente da escrita. A dimensão jurídica está relacionada à invenção da propriedade intelectual, com o Copyright Act de 1609 e o Droit d'auteur no século XVIII. A partir desse momento, o autor passa a estar associado à noção de proprietário. A dimensão estética está ligada à noção tão cara à modernidade de originalidade. A originalidade será uma das bases do direito do autor em sua associação à noção de trabalho. A dimensão referencial é a dimensão relativa ao papel do nome do autor na trama discursiva. Ele tem o papel de classificar, ordenar os discursos.

A questão da autoria está muito em voga na atualidade, devido às discussões relativas à propriedade intelectual na internet e devido à apropriação penal dos usuários em seu acesso às informações na rede. No entanto, nossa reflexão não aponta diretamente a essas questões.

Tomemos o processo projetual. Ele como análise e reflexão contínua sobre a existência transgride aos ditames corriqueiros apresentados pela ecologia de objetos existentes. 0 designer em seu trabalho produz desvios que retransformam sentidos e criam maneiras novas de gerir o espaço e o conhecimento. Esse trabalho quando chega ao fim arbitrário e momentâneo obviamente - dá origem a um produto. Esse produto e o nome do designer ou fabricante se unem nesse momento para marcar seus territórios. Muitas vezes, eles são retomados como índices mercadológicos. 0 nome do autor é comumente usado como garantia de melhor mercadoria, nesse universo tão problemático que é a sociedade de informação. Não só o produto se torna um valor simbólico de uso, como o nome do designer pode se atrelar a tal ponto ao produto, que passa a ser tomado em seu valor de índice de mercadoria. Nesse caso, o nome do autor em sua dimensão referencial é a ponta do processo projetual. É o nome que anuncia seu produto e, por conseguinte, sua morte. 
Os conceitos desenvolvidos em produtos recebem sentido no uso social, sendo aí atribuídos a eles funções e valores. As tecnologias avançam e as técnicas de produção se aprimoram, criando novas possibilidades de manipular matéria e informação. Embora tais avanços tornem gerações inteiras de artefatos obsoletas, por vezes vemos produtos aparentemente ultrapassados receberem novos usos, ressignificando-se e mudando seu posicionamento e atribuições junto aos grupos sociais.

Dessa maneira, transitando entre campos diversos na constituição de seus projetos e lidando com a contínua transformação das práticas, o designer tem no seu trabalho um viés histórico fundamental. Ao gerar elementos que se integrarão à malha cultural, ele entende que, ao interagir com outros objetos, seu trabalho se modificará pelas relações firmadas. Por esses fatores, mostra-se importante mapear o campo de possibilidades de sua produção, compreendendo que seu trabalho não é eterno, mas que tem uma vida e que deve abrir oportunidades de interação com o homem. Cabe dizer que mapear a dinâmica significativa de um artefato no tempo não garante uma única apreensão dele pelo usuário, mas a atenção às possibilidades que se abrem no desenvolvimento de cada projeto.

Cruzando a filosofia da linguagem de Bakhtin (2006) com a epistemologia do campo, vemos que um projeto recorre a múltiplas vozes em seu desenvolvimento. Por seu viés interdisciplinar e pela transgressão implícita na sua prática, o designer recorre a campos associados (LOVE, 2002) para criar parâmetros de trabalho afim de analisar os artefatos que incidem na situação problematizada. Entendemos, como Buchanan (1995), que o design prima pela recombinação, descobrindo o "novo" na rearticulação de fatores (entre os quais, funções presentes em outros artefatos) que convidem usuários a desempenhar funções e liberar novas possibilidades. É aí que se dá o salto inovador, quando, no uso, o indivíduo realiza novas ações e quando o designer atento consegue ligar tais ações a aspectos da solução posta no mundo.

$\mathrm{Na}$ análise da incidência do design na mudança da gestão do espaço laboral, fica claro que o design prima por seguir mudando culturas, a partir de simples modificações nas relações entre sujeitos, objetos e ambientes. Por meio do repertório formado pela ecologia de objetos do presente, o designer busca a melhoria da performance e tal objetivo cria saltos de inovação: (a) no desenvolvimento do trabalho (com geração de múltiplas tentativas de solução satisfatórias); (b) na relação entre o objeto criado e a ecologia em que se insere; (c) na recepção do objeto pelos sujeitos, recepção esta que é permeada (c1) pela relação firmada entre o novo objeto, seus antecessores e seus contemporâneos, (c2) pelas ações 
realizadas por outros sujeitos com aquele objeto e (c3) pela relação entre objeto e a assinatura de seu criador.

A função autor entra aí como vértice de ligação entre produtos novos e usos antigos combinados. A assinatura funciona como ponte entre expectativas baseadas na história dos objetos e novos usos, frutos da combinação entre funções presentes em artefatos anteriores relacionados à mesma situação problemática ou a outras situações. É neste cruzamento que se dá a inovação, que só será confirmada, no entanto, quando a concepção transgressiva do artefato criado for compreendida e, uma vez mais, transgredida pelo público atendido. 0 criador/fabricante da peça se põe, então, como vértice, incluindo na rede de significados ligados a sua assinatura um novo signo e amarrando, em torno de si, uma rede de produtos que trazem o autor como referência.

\section{Referências}

ALMEIDA, L. P. Pensando a sociedade da informação: reflexões sobre o controle e a'homologização' no meio digital. Informação \& Sociedade: Estudos, João Pessoa, v. 17, n. 3, p. 83-90, set./dez. 2007.

ALMEIDA, L. P. Escrita \& autoria: internet, literatura e ontologia. Curitiba: Juruá, 2014.

ARGAN, G. C. A história na metodologia do projeto. Revista Caramelo, São Paulo, n. 6, p. 156-170, 1992.

BAKHTIN, M. M. Estética da criação verbal. 4. ed. São Paulo: Martins Fontes, 2003.

BAKHTIN, M. M. Marxismo e Filosofia da Linguagem: problemas fundamentais do método sociológico da linguagem. 12. ed. São Paulo: Hucitec, 2006.

BAXTER, M. Projeto de produto: guia prático para o design de novos produtos. 3. ed. São Paulo: Blucher, 2011.

BAYMA, F. Educação corporativa: desenvolvendo e gerenciando competências. São Paulo: Pearson Prentice Hall, 2004.

BOMFIM, G. Fundamentos de uma teoria transdisciplinar do design: morfologia dos objetos de uso e sistemas de comunicação. Estudos em Design, Rio de Janeiro, v. 5, n. 2, p. 27-41, 1997.

BOYLE, J. Shamans, software, \& spleens: law and the construction of the information society. London: Harvard University, 1996.

BRUNN, A. L'auteur, textes choisis \& présentés par Alain Brunn. Paris: GF Flammarion, 2001. 
BUCHANAN, R. Wicked problems in design thinking. In: MARGOLIN, V; BUCHANAN, R. (Org). The idea of design. Cambridge: MIT, 1995. p. 5-21.

CHARTIER, R. A aventura do livro, do leitor ao navegador. São Paulo: UNESP, 1998.

COUTO, R. M. S. 0 movimento interdisciplinar de designers brasileiros em busca de educação avançada. 1997. Tese (Doutorado em Educação) - Programa de Pós-graduação em Educação, Pontifícia Universidade Católica do Rio de Janeiro, Rio de Janeiro, 1997.

CROSS, N. Designerly ways of knowing. Design Studies, Oxford, v. 3, n. 4., p. 221-227, 1982.

EAGLETON, T. A ideia da cultura. São Paulo: UNESP, 2005.

FOUCAULT, M. O que é um autor? In: FOUCAULT, M.; MOTTA, M. B.; BARBOSA, I. A. D.

Estética: literatura e pintura, música e cinema. Rio Janeiro: Forense Universitária, 2001. p. 264-298. (Ditos e escritos, 3).

GUATTARI, F.; ROLNIK, S. Micropolítica, as cartografias do desejo. Rio de Janeiro: Vozes, 2007.

HILALI, N. E.; MATHIEU, J. P. Taylorisme, Fordisme et Toyotisme: comment le design management a construit les principaux modèles productifs de la théorie des organisations. In: DESIGN RESEARCH SOCIETY INTERNATIONAL CONFERENCE, DESIGN \& COMPLEXITY, 2010, Montreal. Proceedings... Montreal: Universitè de Montrèal, 2010. p. 31. Disponível em: <http://www.drs2010.umontreal.ca/data/PDF/035.pdf>. Acesso em: 25 jun. 2012.

JOHNSON, S. Cultura da interface: como o computador transforma nossa maneira de criar e comunicar. Rio de Janeiro: JZE, 2001.

KRIPPENDORF, K. On the essential contexts of artifacts or on the proposition that "design is making sense (of things)". In: MARGOLIN, V.; BUCHANAN, R. (Org). The idea of design. Cambridge: MIT Press, 1995. p. 9-39.

LAZZARATO, M. As revoluções do capitalismo. Rio de Janeiro: Civilização Brasileira, 2006.

LOVE, T. Constructing a coherent cross-disciplinary body of theory about designing and designs: some philosophical issues. Design Studies, Oxford, n. 23, n. 3, p. 345-361, 2002.

MANOVICH, L. The language of new media. Cambridge: MIT Press, 2000.

NIETZSCHE, F. 0 livro do filósofo. Porto: Rés,, 1984.

SIMON, H. A. The sciences of the artificial. Cambridge: MIT, 1996. 


\title{
The design as a process and the authorship
}

\begin{abstract}
The current article analyzes the design practice and its relationship with the authorship. We discuss the copyright figure in the design in light of the reflection on the projective dimension of the designer's work. We consider, therefore, the products of this labor as isolated events in a spiral cycle in constant development.
\end{abstract}

\section{Keywords}

Epistemology. Authorship. Design process.

Recebido em: 03/12/2014

Aceito em: 10/04/2015 